\title{
DESENVOLVIMENTO DE UM HIDROCICLONE PARA SEPARAÇÃO DE ÁGUA DISPERSA EM ÓLEO
}

\author{
J. P. S. de Oliveira, R. A. Medronho e T. S. Klein \\ Universidade Federal do Rio de Janeiro, Escola de Química \\ E-mail para contato: joaopedrooliveira@eq.ufrj.br
}

\begin{abstract}
RESUMO - Neste trabalho, desenvolveu-se um hidrociclone para a separação de gotas de água dispersas em óleo. Para tanto, realizaram-se simulações de CFD em conjunto com a técnica de DCCR. No estudo realizado, simulações CFD de nove modelos relativos a combinações de diâmetros de overflow e underflow foram conduzidas, fixando-se a concentração de água em 10\%, em volume, e gotas com $50 \mu \mathrm{m}$. As medidas de $1,56 \mathrm{~cm}$ e $1,28 \mathrm{~cm}$ para underflow e overflow, respectivamente, retornaram os melhores resultados, com eficiência granulométrica de $63 \%$ e razão de fluido de $37 \%$. Para determinação do desempenho, realizaramse simulações com vários diâmetros de gota, mantendo a concentração, obtendo-se a curva de eficiência granulométrica reduzida e o diâmetro de corte reduzido como sendo igual a $57 \mu \mathrm{m}$.
\end{abstract}

\section{INTRODUÇÃO}

Hidrociclones consistem em equipamentos ciclônicos que promovem a separação de uma fase dispersa de outra contínua, de densidades diferentes, pelo princípio da sedimentação em campo centrífugo. No presente trabalho, desenvolveu-se um hidrociclone para separar água dispersa em óleo, no sentido de contribuir para a investigação de tecnologias a serem aplicadas em sistemas submarinos (subsea) de processamento de óleo e gás. A metodologia utilizada é similar à de Araújo (2015) e Braga (2015), que desenvolveram hidrociclones destinados ao condicionamento de águas oleosas. Porém, a separação de gotas de água dispersas em óleo apresenta um maior grau de dificuldade devido, principalmente, aos altos valores de viscosidade dos óleos.

\section{METODOLOGIA}

A metodologia do presente trabalho consistiu em se partir de uma geometria base e utilizar uma técnica de planejamento experimental para definir as demais geometrias a serem estudadas de modo que, através de simulações com Fluidodinâmica Computacional (CFD), se possa identificar aquela que retorna o melhor desempenho.

A geometria básica escolhida foi semelhante à de um hidrociclone de Bradley com 10 $\mathrm{cm}$ de diâmetro, empregando-se, porém, duas entradas retangulares com razão largura/altura de $1 / 2$, mantendo-se a mesma área de entrada. Cálculos preliminares indicaram que, para tal geometria, gotas de água de $50 \mu \mathrm{m}$ de diâmetro retornariam eficiências granulométricas na faixa 


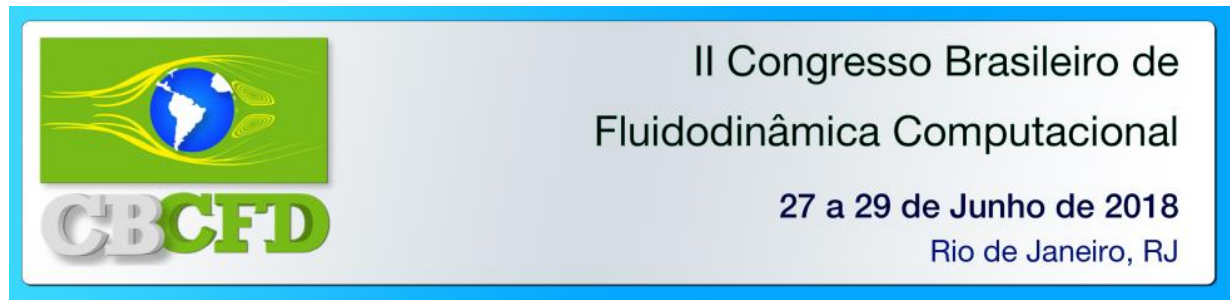

de $50 \%$, que são adequadas para avaliar a sensibilidade desse parâmetro a mudanças na geometria do hidrociclone.

\subsection{Planejamento Experimental}

As variáveis independentes do planejamento experimental foram os diâmetros dos tubos de saída de overflow e de underflow, empregando-se as faixas de 0,7-2,3 cm e 0,5-1,5 cm, respectivamente. Tomou-se como respostas a eficiência granulométrica $(\mathrm{G})$ e a razão de fluido $\left(\mathrm{R}_{\mathrm{f}}\right)$, que são parâmetros de performance em hidrociclones.

A aplicação da técnica de delineamento composto central rotacional, que admite a obtenção de modelos quadráticos, levou a uma composição da matriz de experimentos abrangendo 4 casos fatoriais, 4 pontos axiais e 1 ponto central, totalizando 9 simulações a serem conduzidas com CFD. Em sendo um tratamento do tipo rotacional, os níveis axiais com $\alpha=\sqrt{2}$, além de permitirem correlações não lineares, expandem a área de estudo de maneira a expressar o comportamento das respostas em uma maior extensão. A seleção dos níveis para dimensionamento do hidrociclone decorreu da metodologia de otimização simultânea desirability. Para processar os dados resultantes, utilizou-se o software comercial Statistica ${ }^{\circledR}$.

As condições de operação adotadas para os tratamentos do planejamento incluem: densidades das fases contínua (óleo) e discreta (água) iguais a 0,9 g.cm ${ }^{-3}$ e 1,03 g.cm respectivamente, viscosidade do óleo de $2 \mathrm{cP}$ e vazão processada dada por $924 \mathrm{~cm}^{3} \cdot \mathrm{s}^{-1}$ (correspondendo à velocidade superficial de $6 \mathrm{~m} \mathrm{~s}^{-1}$ ).

A Tabela 1 resume a geometria de cada um dos nove hidrociclones simulados e já inclui os valores de eficiência granulométrica para gotas de água de $50 \mu \mathrm{m}$ e a razão de fluido encontrados para cada configuração geométrica.

Tabela 1 - Matriz de experimentos após as corridas.

\begin{tabular}{cccccccc}
\hline Tratamento & $\mathrm{D}_{\mathrm{o}}$ & $\mathrm{D}_{\mathrm{u}}$ & $\mathrm{D}_{\mathrm{o}}(\mathrm{cm})$ & $\mathrm{D}_{\mathrm{u}}(\mathrm{cm})$ & $\mathrm{G}(\%)$ & $\mathrm{R}_{\mathrm{f}}(\%)$ & $\mathrm{G}^{\prime}(\%)$ \\
\hline HC1 & +1 & -1 & 2,30 & 0,50 & 8,9 & 1,1 & 7,9 \\
HC2 & +1 & +1 & 2,30 & 1,50 & 46,7 & 20,1 & 33,3 \\
HC3 & -1 & -1 & 0,70 & 0,50 & 56,1 & 36,8 & 30,5 \\
HC4 & -1 & +1 & 0,70 & 1,50 & 96,1 & 86,1 & 72,2 \\
HC5 & $+1,41$ & 0 & 2,63 & 1,00 & 18,6 & 4,9 & 14,4 \\
HC6 & $-1,41$ & 0 & 0,37 & 1,00 & 98,7 & 90,6 & 85,7 \\
HC7 & 0 & $+1,41$ & 1,50 & 1,70 & 80,3 & 58,8 & 52,2 \\
HC8 & 0 & $-1,41$ & 1,50 & 0,30 & 13,2 & 2,5 & 11,0 \\
HC9 & 0 & 0 & 1,50 & 1,00 & 53,2 & 29,2 & 33,8 \\
\hline
\end{tabular}

\subsection{Simulações com CFD}

A geometria do hidrociclone proposto, bem como a malha computacional utilizada, com cerca de 560 mil nós podem ser vistas na Figura 1. Um teste de malha foi conduzido para garantir a independência dos resultados com relação à malha. Os softwares do pacote comercial 


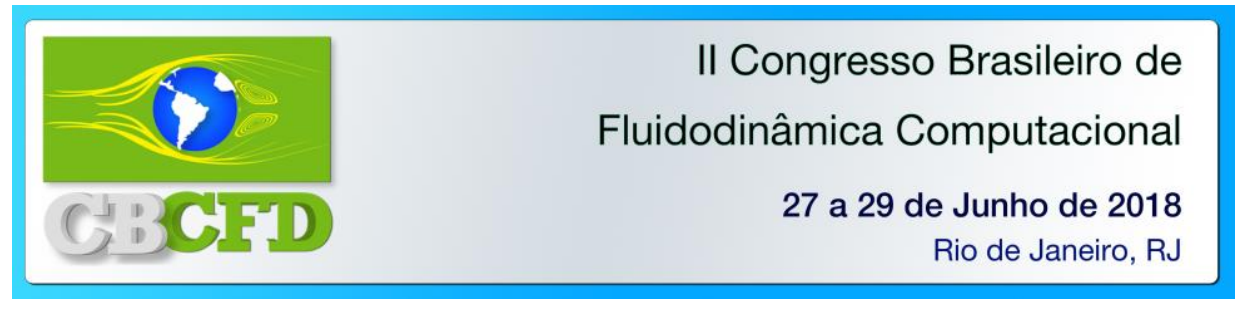

da ANSYS $^{\circledR}$ v18.0 foram usados para todas as etapas das simulações: DesignModeler ${ }^{\circledR}$, ICEM CFD $^{\circledR}$, Fluent ${ }^{\circledR}$ e CFD-Post.

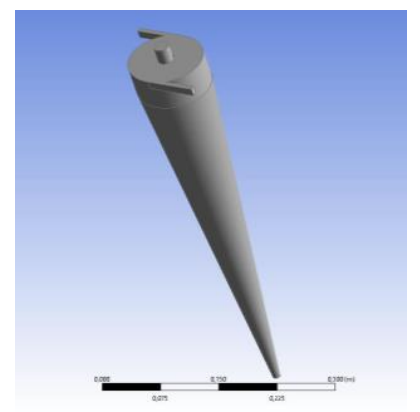

(b)

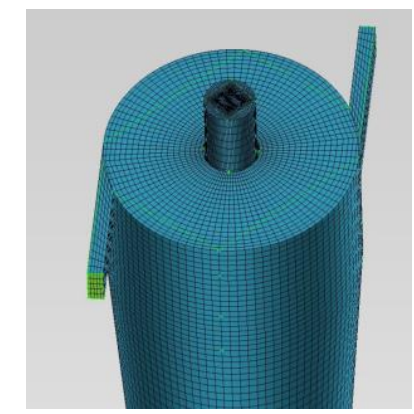

(a)

Figura 1 - (a) Geometria. (b) Malha do hidrociclone proposto.

O tratamento fenomenológico do escoamento considerado nas simulações consiste na aplicação das equações de transporte representativas dos princípios de conservação de massa (continuidade) e de momento linear. O escoamento bifásico, constituído pelas fases oleosa (contínua) e aquosa (dispersa), foi tratado pela abordagem Euler-Euler, com gotas de água de diâmetro constante $(50 \mu \mathrm{m}$ para as nove simulações do planejamento e variações entre $10 \mu \mathrm{m}$ e $120 \mu \mathrm{m}$, de $10 \mathrm{em} 10 \mu \mathrm{m}$, para construção da curva de eficiência granulométrica). Tal abordagem se fundamenta em solucionar as equações de quantidade de movimento individualmente para cada fase, o que leva a campos de velocidade diferenciados, para um mesmo campo de pressão, junto à equação da continuidade para o sistema global e à equação de fração volumétrica para uma das fases.

Devido ao escoamento complexo que ocorre em hidrociclones, o modelo de turbulência utilizado foi o de Gibson e Launder (1978), pertencente à classe de modelos de tensores de Reynolds. As condições de contorno especificadas foram: velocidade uniforme de $6 \mathrm{~ms}^{-1} \mathrm{com}$ fração volumétrica da fase dispersa de $10 \%$ para as duas seções de entrada tangenciais; valor nulo para a pressão manométrica no overflow e underflow; e condição de aderência nas paredes. No que tange à discretização dos termos de fluxo, aplicou-se o esquema centrado de $2^{\mathrm{a}}$ ordem (CDS) para os difusivos e o esquema de interpolação QUICK para os termos advectivos. Ainda, a formulação pseudo-transiente foi empregada para conduzir as simulações estacionárias com o objetivo de favorecer sua convergência. Sua utilização em substituição ao tratamento transiente, como alternativa para superar as dificuldades numéricas encontradas com simulações em regime permanente diretamente, se mostrou eficaz no estudo comparativo desenvolvido por Anjos et al. (2017). Alcançaram-se resíduos da ordem de $10^{-5}$ para as equações da continuidade e de Navier-Stokes e de $10^{-3}$ para as de turbulência.

\section{RESULTADOS E DISCUSSÃO}

\subsection{Planejamento Experimental}

As Equações (1), para a eficiência granulométrica, e (2), para a razão de fluido, são as correlações obtidas pelo ajuste estatístico dos dados provenientes das simulações. Através da metodologia de otimização simultânea, visando a maximizar $G$ e minimizar $R_{f}$, os valores ótimos para os diâmetros de overflow e underflow foram de $1,55 \mathrm{~cm}$ e 1,26 cm respectivamente. 


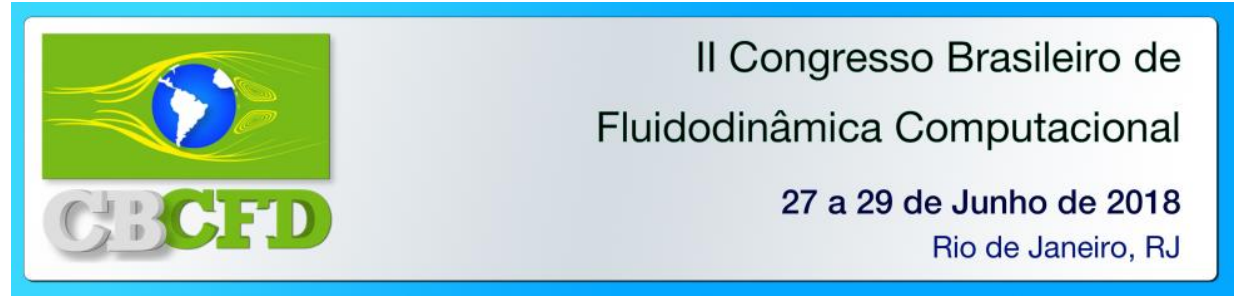

$$
\begin{aligned}
& G=45,28-7,844 D_{o}^{2}-9,319 D_{o}+43,22 D_{u} \\
& R_{f}=46,15+13,37 D_{o}^{2}-56,08 D_{o}+65,35 D_{u}-18,91 D_{o} D_{u}
\end{aligned}
$$

\subsection{Avaliação do Desempenho do Hidrociclone Obtido}

A curva de eficiência granulométrica reduzida do hidrociclone projetado pode ser vista na Figura 2. Com base nesta, estimou-se o diâmetro de corte reduzido do hidrociclone em 57 $\mu \mathrm{m}$, o que permite a realização de previsões de performance pelo cálculo da eficiência total reduzida em função da distribuição de tamanhos das gotas nas seções de entrada.

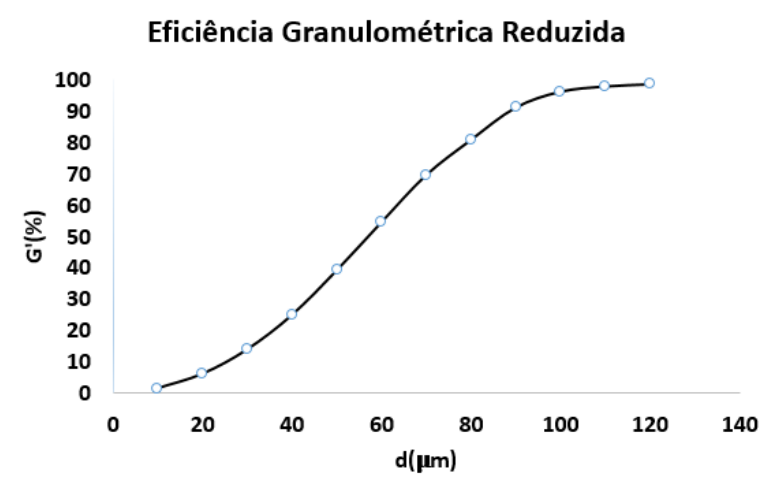

Figura 2 - Curva de eficiência granulométrica reduzida do hidrociclone projetado.

\section{CONSIDERAÇÕES FINAIS}

Mediante as ferramentas de CFD e de planejamento experimental, obteve-se um hidrociclone para separar gotas de água dispersa em óleo. $\mathrm{O}$ dispositivo dimensionado produz um diâmetro de corte reduzido de $57 \mu \mathrm{m}$, quando tratando uma vazão de $900 \mathrm{~cm}^{3} \mathrm{~s}^{-1}$. Os trabalhos futuros desta pesquisa consistem na validação das simulações realizadas através da verificação dos perfis de velocidades, com PIV, e na construção do hidrociclone para testes experimentais.

\section{REFERÊNCIAS BIBLIOGRÁFICAS}

ANJOS, R. P.; OLIVEIRA, R. S.; MEDRONHO, R. A. Numerical Simulation of a Bradley Mini-Hydrocyclone. Proc. of the 7th Int. Conference on Advances in Applied Science and Environmental Technology - ASET. Bangkok: IRED Headquarters, p. 20-23, 2017.

ARAÚJO, C. A. O. D. Hidrociclones para a Separação de Misturas de Alto Teor de Óleo Disperso em Água. Tese de doutorado, Programa de Tecnologia dos Processos Químicos e Bioquímicos, Escola de Química, UFRJ. Rio de Janeiro, p. 119. 2015.

BRAGA, E. R. Desenvolvimento de um Hidrociclone para Separação do Óleo Presente em Águas Oleosas de Refinarias de Petróleo. Tese de Doutorado, Programa de Tecnologia dos Processos Químicos e Bioquímicos, Escola de Química, Rio de Janeiro, p. 163. 2015.

GIBSON, M. AND LAUNDER, B. Ground Effects on Pressure Fluctuations in the Atmospheric Boundary Layer. J. Fluid Mech, v. 86, p. 491-511, 1978. 